\title{
Phase 1 Study of an Inactivated Vaccine against American Tegumentary Leishmaniasis in Normal Volunteers in Brazil
}

\section{Keyla BF Marzochi/ ${ }^{+}$, Mauro CA Marzochi*, Aline F Silva*, Neiva Grativol, Rosemere Duarte*, Eliame Mouta Confort*, Farrokh Modabber**}

\begin{abstract}
Hospital Evandro Chagas, Instituto Oswaldo Cruz, Av. Brasil 4365, 21045-900 Rio de Janeiro, RJ, Brasil *Departamento de Ciências Biológicas, Escola Nacional de Saúde Pública, Fiocruz, Rua Leopoldo Bulhões 1480, 21041-210 Rio de Janeiro, RJ, Brasil **WHO/TDRHQ, Geneva

A Phase 1 double-blind placebo-controlled study was performed to evaluate a vaccine against American tegumentary leishmaniasis in 61 healthy male volunteers. Side effects and the immune response to the vaccine were evaluated, with 1- and 2-dose schemes, with intervals of 7 or 21 days, each dose containing $1440 \mathrm{mg}$ of protein $N$ antigen of a single strain of Leishmania amazonensis (PH 8) diluted in merthiolated saline (1:10,000). Merthiolated saline and an inert substance were used as placebos. No significant clinical alterations were found following the respective injections in the vaccinated individuals as compared to the placebos, except for local pain, which was associated significantly with injection of the vaccine. The laboratory alterations we observed bore no association with the clinical findings and were unimportant. We observed no differences between the groups with regard to seroconversion or the Montenegro skin test. However, the group that received a single dose of the vaccine and the one that received two doses with a 21-day interval displayed cutaneous induration significantly larger than in the control group, with 100\%, 100\%, and 66\% conversion in the skin test, respectively. We concluded that the vaccine does not present any major side effect that would contraindicate its use in healthy individuals.
\end{abstract}

Key words: Leishmania - vaccine - Phase I study - side effects - Montenegro skin test

American tegumentary leishmaniasis (ATL) is an endemic anthropozoonosis undergoing expansion on the American continent. Its importance is due to its broad range of clinical manifestations, varying from self-limiting localized cutaneous lesions to disfiguring lesions in the mucosal and diffuse forms, in addition to the difficulties encountered in treatment and control. Pentavalent antimonials, the main drugs currently used, are highly toxic and expensive and require prolonged treatment schemata, and some forms of the disease are resistant to this treatment (Bryceson 1987, Olliaro \& Bryceson 1993). On-going research on alternative drugs is being done, and the action of immunotherapy is being assessed (Badaró \& Johnson Jr 1993, Monjour et al. 1994). In Brazil the incidence coefficient varies from 93.07 cases

This investigation received financial support from the UNDP/World Bank/WHO Special Program for Research and Training in Tropical Diseases.

${ }^{+}$Corresponding author. Fax +55-21-590.9988. E-mail: keylabfm@dcc001.cict.fiocruz.br.

Received 25 March 1997

Accepted 10 September 1997 per 100,000 inhabitants in the Northern region (Amazônia) to 3.91/100,000 inhabitants in the Southern region, with 31,713 cases notified in 1994 (Marzochi \& Marzochi 1994).

In Brazil, there are at least six species of dermotropic Leishmania for humans in various ecological situations (Lainson et al. 1994). Control is thus complex, and there are different patterns of transmission (Marzochi \& Marzochi 1994). In the Amazon region it implies human contact with forests through participation of sylvatic reservoirs and various sandfly vectors. In areas that have been settled longer, transmission is generally rural and peridomiciliary, and there is discussion concerning possible sources of infection such as canines, equids, rodents, and humans, as well as association with various species of sandflies which adapt well to altered environments (Desjeux 1992, Marzochi 1992, Lainson et al. 1994, Marzochi \& Marzochi 1994). Subclinical infection is highly frequent (Marzochi et al. 1980, Isaza 1980, Guerra et al. 1985, Cordova-Uscanga et al. 1993) and probably underestimated. Current control methods oriented towards combating the vector are also debatable and limited to peridomiciliary transmission (Marzochi \& Marzochi 1994, Oliveira Filho \& Melo 1994). 
Utilization of a vaccine against ATL in Brazil was a pioneering initiative; produced on the basis of cultures of killed parasites, it led to a reduction in the number of disease cases in the populations studied (Salles Gomes 1939, Pessoa \& Pestana 1940, Pessoa 1941). However, these studies were abandoned, probably due to the decline in the incidence of ATL in old endemic areas. More recently, vaccination studies in new areas yield results that agreed with these previous studies, due to acquisition of protective immunity, assessed principally by post-vaccinal conversion of the Montenegro skin test (leishmanin) (Mayrink et al. 1979, 1985, Antunes et al. 1986, Castés et al. 1994).

In the Old World, vaccination was employed with live promastigote forms of $L$. major using intradermal innoculation (Nadim 1990), and considerable reduction was also achieved in the number of cases of the disease among vaccinated individuals, although the side effects were considerable, leading to interruption of the tests.

The evaluation of the Leishmania vaccine in this research stems from studies by Mayrink et al. $(1979,1985)$ producing a vaccine with killed promastigote forms from a pool of Leishmania strains (240 mg of protein nitrogen per dose) and immunizing a population from an endemic area for this disease, obtaining $78.4 \%$ of conversion for the Montenegro skin test in previously negative individuals; in a new test, using the same antigen in a population from a different area, some $85 \%$ of conversion for the Montenegro skin test and a significantly lower incidence rate for the disease were achieved. Factors such as the disappearance of ATL in the area studied in 1979 and a major population migration observed in 1985 hindranded evaluation of results.

Later, in a controlled study, with the same vaccine, on military personnel headquartered in an endemic area, Antunes et al. (1986) observed similar disease incidence rates among vaccinated and non-vaccinated individuals, although there was a significant predominance of conversion in the Montenegro skin test in the vaccinated group. The authors attributed the disease incidence rate in the vaccinated individuals to immunosuppression caused by immunization for yellow fever shortly after the vaccination for leishmaniasis.

Beginning in 1988 the ATL vaccine proposed by Mayrink et al. (1985) began commercial production with the name LEISHVACINò however, based on a recommendation by the World Health Organization (WHO), from there on it was composed of a single strain of Leishmania, and the reference PH8 strain of L. amazonensis (IFLA/BR/ $67 / \mathrm{PH} 8$ ) belonging to the initial pool was selected.
Although no side effects have been observed in the utilization of this vaccine in Brazil, thus far no well-controlled assessment of this has been done in the various studies cited above. The objective of this Phase 1 study was to perform an analysis of possible clinical and laboratory side effects of LEISHVACINÒ, constituted from a single strain of Leishmania and with a greater concentration of antigen (1440 $\mathrm{mg}$ of protein nitrogen per dose) in normal volunteers.

\section{MATERIALS AND METHODS}

Before started, the study was submitted and approved by an institutional human subjects committee responsible for monitoring the ethical conduct of research involving human subjects of the Oswaldo Cruz Foundation (Fiocruz).

Volunteers and skin test - The study initially included 206 male military volunteers ranging from 18 to 40 years of age, headquartered at a military unit in Rio de Janeiro, who were submitted to an initial Montenegro skin test corresponding to 0.1 $\mathrm{ml}$ containing $40 \mathrm{mg}$ of protein nitrogen/ $\mathrm{ml}$ of standardized antigen (Melo et al. 1977), produced with 5 strains of Leishmania (the same composition as that of the vaccine described by Mayrink et al. 1979), according to Good Manufacturing Processes (GMP), applied intradermally on the anterior surface of the forearm. The reading was performed and recorded after $48 \mathrm{hr}$, by stamping the papule on paper (Sokal 1975). Individuals with a negative response, with induration less than or equal to $5 \mathrm{~mm}$ along the longest diameter were accepted for the vaccination protocol, making a total of 61 volunteers. All of these individuals also had negative serology for HIV and Trypanosoma cruzi, had no signs or symptoms of infectious or chronic degenerative disease, and denied skin allergies. None of them had a previous or recent history or scars compatible with leishmaniasis. One individual, who was a chronic hepatitis $\mathrm{C}$ carrier, expressed his desire to participate as a volunteer, and signed a second, specific term of responsibility in addition to the protocol term.

Vaccine - The vaccine used in the study (BIOBRAS, S/A) was produced according to GMP and Mayrink et al. (1979), but only with the PH8 (L. amazonensis) strain, at a concentration of 1440 $\mathrm{mg}$ of protein nitrogen per dose, made up of $50 \%$ of whole promastigote forms of the parasite and $50 \%$ of macerated material, all diluted in merthiolated saline at 1:10,000.

Placebo - Two types of placebo were used, in the control group, consisting of the vaccine vehicle, 1:10,000 merthiolated saline, and an inert substance, physiological saline.

Vaccinal scheme - The vaccine or placebo was 
applied IM (left deltoid region) in doses of $1.5 \mathrm{ml}$ on days 0,7 , and 21 of the study, in double-blind fashion. The volunteers were divided into groups according to the scheme presented in Table I.

Non-specific clinical and laboratory evaluation - Clinical examination was performed before each injection and was repeated at $24 \mathrm{hr}, 72 \mathrm{hr}$, and 7 days. Blood samples were taken at the same time (without prior fasting) for the following laboratory tests: blood - CBC, ESR, platelets; hepatic function - SGOT, SGPT (Celm), PT, bilirubin (Merck), LDH, alkaline phosphatase (Biotrol), GGT (Merck); and renal function - urea (Merck) and creatinine (Celm). We defined laboratory alteration as any deviation outside the standard limits of the test, regardless of clinical correlation.

Evaluation of immune response - This was measured 20 days after the final injection. The cellular immune response was assessed on the basis of positive conversion in the Montenegro skin test, with induration $>5 \mathrm{~mm}$, using the same antigen and procedure as in the initial test. Diameters of induration were also observed in the different groups. The serological response was evaluated by indirect immunofluorescence (IIF) with L. majorlike antigen (Marzochi et al. 1980) and ELISA (Voller et al. 1976), with antigen from the same parasite, and negative serology was considered that below dilution of 1:40 for both tests.

Statistical analysis - The data were analyzed utilizing the following tests: Fischer's exact and Kruskal-Wallis.

\section{RESULTS}

Clinical evaluation - Table II shows the percentage of clinical alterations found by group, per injection. All manifestations reported by volunteers were catalogued, as well as alterations observed at the injection site and systemic alterations. Mild or moderate local pain was the most frequently reported effect in all of the groups and was more frequently associated with injections of LEISHVACINÒ . Vaccinated individuals had a significantly greater frequency than the placebo group while the group, with the autoclaved double vaccine $(\mathrm{G} \mathrm{V})$ had the lowest frequency among the vaccinated groups, mainly compared to the group submitted to the same scheme, with a non-autoclaved vaccine (G IV). The local pain never extended beyond $24 \mathrm{hr}$, was not accompanied by other local inflammatory signs or regional lymph node enlargement, nor did it require specific treatment except in the case of two volunteers who self-medicated, and it did not jeopardize physical activity in the barracks among the volunteer who did present this side effect. In one case only, the second dose of the vaccine set off a erythematous-pruriginous reaction at the site of application. Other reactions as described in Table I had similar frequencies among the various groups, including the placebo group, and it was not possible to associate them with any specific type of injection, nor did they require treatment. At no point in the study did the volunteers have to interrupt their normal physical and intellectual activities, nor was there any report of harm to their activities following application of the injections.

Laboratory evaluation - Table III shows the frequency of alternations in laboratory tests as found before the trial began and after injections of placebos and vaccine in the various groups. At these various moments the proportions of altered tests were similar.

No case to case correlation was observed between the clinical and laboratory alterations for any volunteer, whether he was from the placebo group or the vaccinated group after receiving vaccine or placebo.

TABLE I

Schemes for application of LEISHVACINÒ and placebo in double blind study

\begin{tabular}{|c|c|c|c|c|c|}
\hline Groups & Schemes & Injection, day 0 & Injection, day 7 & Injection, day 21 & $\begin{array}{l}\text { No. of } \\
\text { volunteers }\end{array}$ \\
\hline GI & Placebo & $\begin{array}{l}\text { Merthiolated } \\
\text { saline }\end{array}$ & $\begin{array}{l}\text { Physiological } \\
\text { saline }\end{array}$ & Merthiolated saline & 12 \\
\hline GII & $\begin{array}{l}\text { Vaccine, } \\
\text { single dose }\end{array}$ & LEISHVACIN $^{\circledR}$ & $\begin{array}{l}\text { Physiological } \\
\text { saline }\end{array}$ & Merthiolated saline & 12 \\
\hline GIII & $\begin{array}{l}\text { Vaccine, } \\
\text { double dose }\end{array}$ & LEISHVACIN $^{\circledR}$ & LEISHVACIN $^{\circledR}$ & Merthiolated saline & 13 \\
\hline GIV & $\begin{array}{l}\text { Vaccine, } \\
\text { double dose }\end{array}$ & LEISHVACIN $^{\circledR}$ & $\begin{array}{l}\text { Physiological } \\
\text { saline }\end{array}$ & LEISHVACIN $^{\circledR}$ & 12 \\
\hline GV & $\begin{array}{l}\text { Autoclaved vaccine, } \\
\text { double dose }\end{array}$ & $\begin{array}{l}\text { LEISHVACIN }^{\circledR} \\
\text { autoclaved }\end{array}$ & $\begin{array}{l}\text { physiological } \\
\text { saline }\end{array}$ & $\begin{array}{l}\text { LEISHVACIN }^{\circledR} \\
\text { autoclaved }\end{array}$ & 12 \\
\hline
\end{tabular}




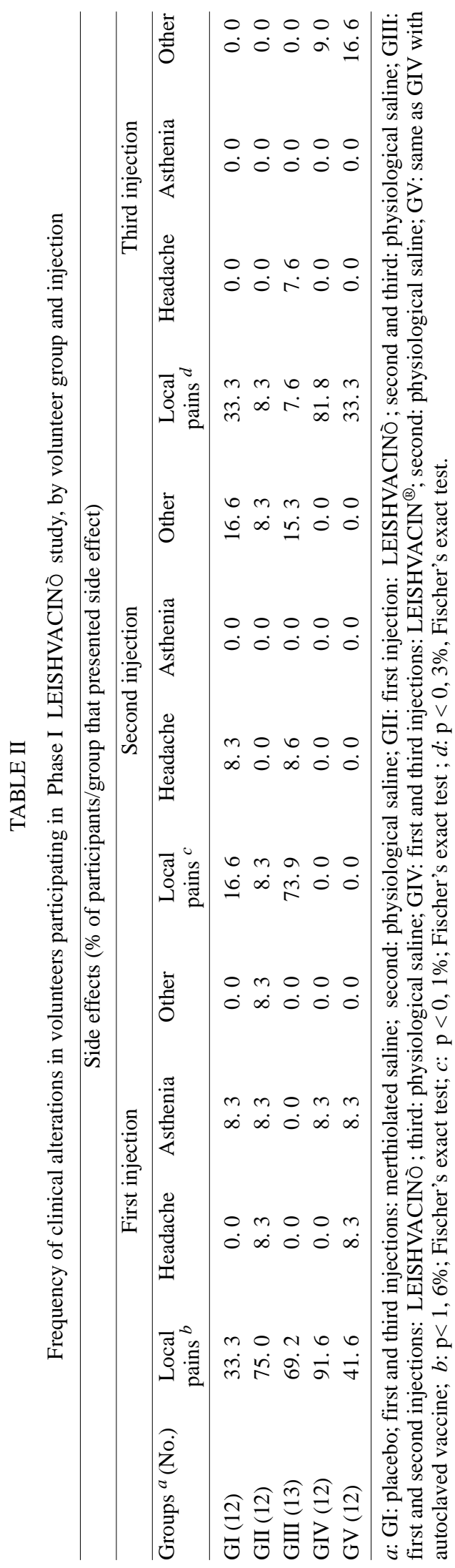

Evaluation of immune response - Conversion of the Montenegro skin test (> $5 \mathrm{~mm}$ ) occurred in all of the groups, including the placebo group, at rates varying from 66.6 to $100 \%$, with no significant difference (Table IV). However, in addition to presenting $100 \%$ conversion, the groups that received the single dose scheme and the double dose scheme with a 21 day interval presented greater intensity of local induration as compared to the other groups, with sizes of reactions that were significantly larger $(\mathrm{p}<0.14)$ compared to the placebo group. The lowest conversion rate amongst the vaccinated groups was the one in which the volunteers received autoclaved vaccine.

Conversion to the Montenegro skin test did not vary when classifying volunteers by either place of origin or duration and type of military service (cadets and career personnel).

Serological evaluation - The serological response displayed very low positive conversion indices for the tests used, did not follow the positive conversion for the skin test, nor did it correlate with any group or injection.

\section{DISCUSSION}

The results obtained in this study corroborate those of previous studies which - although not having this objective - did not demonstrate the presence of side effects in the utilization of ATL vaccine produced with killed promastigotes, lower antigen concentration, and pool of strains (Pessoa \& Pestana 1940, Pessoa 1941, Mayrink et al. 1979, 1985, Antunes et al. 1986). In the clinical and laboratory sense, the vaccine utilized in this study may be considered innocuous, since it was not possible to associate it with any parallel event of a serious nature in schemes of one dose or two doses with 7 and 21 day intervals.

The clinical condition of the volunteers did not present substantial alterations that could be associated significantly with injections of LEISHVACINò , and symptoms were reported after injections of placebo in all of the groups studied. Observation of such symptoms can be explained by different degrees of sensitivity to pain, a variable reaction to the physical discomfort that is common to deep intramuscular injections. Frequency of pain in the placebo group, which was higher when the merthiolated saline was used (in the same concentration as that employed in the vaccine), merely indicates the occurrence of non-specific side effects that can be associated with Thiomersal. This dilutant, used in domestic and professional routine as a topical antiseptic and also included in numerous other vaccines, has been implicated in reactions of an allergic nature (Mallory 1987), and there have even been suggestions that it be removed from the composition of 
TABLE III

Frequency of laboratory alterations in volunteers, based on number of tests/day and injection applied

\begin{tabular}{llcccccc}
\hline Date & Injection $^{a}\left({ }^{b}\right)$ & Leucoytes $^{c}$ & Eosinohils $^{c}$ & Neutrophils $^{c}$ & Lymphocytes $^{c}$ & Urea $^{d}$ & PT $^{e}$ \\
\hline Prior test & None & 0.08 & 0.04 & 0.16 & 0.24 & 0.26 & 0.016 \\
\hline \multirow{2}{*}{ Day 0 (No.) } & Vaccine N (37) & 0.08 & 0.13 & 0.21 & 0.29 & 0.45 & 0.08 \\
& Vaccine A (12) & 0.16 & 0.16 & 0.33 & 0.41 & 0.08 & 0.08 \\
& Placebo M (12) & 0.08 & 0.16 & 0.33 & 0.33 & 0.08 & 0.00 \\
Day 7 (No.) & Placebo I (37) & 0.02 & 0.08 & 0.32 & 0.45 & 0.18 & 0.00 \\
& Vaccine N (12) & 0.08 & 0.33 & 0.41 & 0.41 & 0.25 & 0.08 \\
& Placebo I (25) & 0.16 & 0.24 & 0.28 & 0.28 & 0.24 & 0.16 \\
Day 21 (No.) & Placebo M (12) & 0.00 & 0.16 & 0.25 & 0.41 & 0.16 & 0.00 \\
& Vaccine N (12) & 0.16 & 0.25 & 0.50 & 0.50 & 0.08 & 0.33 \\
& Vaccine A (12) & 0.33 & 0.41 & 0.41 & 0.66 & 0.08 & 0.16 \\
\hline
\end{tabular}

Types of injection $a$ : Vaccine N: non-autoclaved vaccine; Vaccine A: autoclaved vaccine; Placebo M : merthiolated saline (at 1:10000); Placebo I: physiological saline $\left(\mathrm{N}^{b}\right)$ : number of tests; $c$ : frequency of alterations in number of cells $d$ : frequency of alterations in blood urea levels; $e$ : frequency of alterations in prothrombin time.

\section{TABLE IV}

Response of volunteers of LEISHVACINÒ phase I study to the second intradermal test, 47 days after first injection

\begin{tabular}{lccccc}
\hline \multicolumn{5}{c}{ Montenegro skin test $(\%$ of positive volunteers/group, according to enduration diameter) } \\
\hline & $<5 \mathrm{~mm}$ & ${ }^{3} 5 \mathrm{~mm}<10 \mathrm{~mm}$ & ${ }^{3} 10 \mathrm{~mm}$ & Total & Mean induration \\
\cline { 2 - 6 } Groups $^{a}$ (No.) & No. $(\%)$ & No. $(\%)$ & No. $(\%)$ & $>5 \mathrm{~mm}$ & $(\mathrm{~mm})$ \\
\hline GI (12) & $4(33.40)$ & $2(16.6)$ & $6(50.00)$ & $8(66.6)$ & 8.58 \\
GII (12) & $0(0.00)$ & $1(8.33)$ & $11(91.66)$ & $12(100.0)$ & $13.66^{b}$ \\
GIII (13) & $1(7.70)$ & $2(16.6)$ & $10(76.90)$ & $12(95.6)$ & 10.53 \\
GIV (12) & $0(0.00)$ & $2(16.6)$ & $10(83.30)$ & $12(100.0)$ & $14.25^{b}$ \\
GV (12) & $2(16.70)$ & $1(8.33)$ & $9(75.00)$ & $10(83.33)$ & 11.58 \\
\hline Total (61) & $7(11.47)$ & $8(13.11)$ & $46(75.40)$ & $54(88.51)$ & - \\
\hline
\end{tabular}

$a$ : GI : placebo; first and third injections: merthiolated saline; second: physiological saline; GII: first injection: LEISHVACINÒ ; second and third: physiological saline; GIII: first and second injections: LEISHVACINò ; third: physiological saline; GIV: first and third injections: LEISHVACIN®; second: physiological saline; GV: same as GIV with autoclaved vaccine; ${ }^{b}$ p: 0,14 vs placebo group, Kruskall- Wallis test.

routine vaccines (Scarpa et al. 1992, De La Quadra 1993, Handley et al. 1993).

Pain at the site of application, associated significantly with injections of vaccine, was mild in nature and did not interfere with the volunteers' normal activities, even those requiring physical effort. It was compatible with the pain caused by other vaccines traditionally in use, and was described by some volunteers as "milder than that caused by the tetanus toxoid (TT)". The autoclaved vaccine presented a lower frequency of local pain as compared to the other vaccinated groups, after both the first injection and the second one after 21 days. The autoclave process may have fractionated the whole promastigotes, facilitating their absorption and reducing pain.

As a general rule, the laboratory tests used in this study should be evaluated in light of the individual's clinical status, and never in isolation. Nonetheless, there were no significant differences as to the frequency of results outside the limits of the standard for normality, either before or after applications of vaccine and placebo. However, among the hematological alterations, only eosinophilia was more frequent both after injection of placebo and that of vaccine as compared to day zero (Table II), although this was not statistically significant. This rise may be explained by the presence of merthiolate in the vaccine and in almost all of the placebo injections (except for one group of 12 volunteers who received saline without merthiolate, once). In the general population, allergy to merthiolate is reported as $51 \%$ (Moriearty et al. 1978). 
As for the biochemical tests, there was also no difference in the frequency of alterations observed before and after injections for the tests as a whole. The increases in waste nitrogen in some tests, regardless of whether before or after injections of vaccine or placebo, are associated with the absence of fasting among the volunteers.

In relation to evaluation of the immune response, several factors may have interfered in the results (Table III), requiring further assessment.

The conversion rate observed for the Montenegro skin test, was the highest as compared to previous studies, even considering a cut-off of $10 \mathrm{~mm}$ of induration, based on a recommendation by the World Health Organization (Castés et al. 1994). Nevertheless, we were unable to associate it definitively with injections of the vaccine, since we found a significant conversion rate for the skin test in the placebo group. We attempted to correlate this rate to exposure of volunteers to an endemic leishmaniasis area, where they stayed for two days during the study period and during which some received a third dose of TT. However, when we compare the response to the Montenegro skin test among volunteers who experienced this exposure to those who were not exposed (data not shown), we failed to find statistically significant differences. Neither did the third dose of TT display interference in this response.

The dilutant and the method used for evaluation in this study deserve further consideration. The dilutant used originally was phenol (Salles Gomes 1939, Pessoa \& Pestana 1940), later replaced by merthiolate (Mayrink et al. 1979). However, allergic reactions have been described for Merthiolate that are similar to the cutaneous reactions to the Montenegro test, due to the mechanisms involved in the morphology of the reaction (type IV cellular hypersensitivity reaction) (Mallory 1987). Therefore, we cannot rule out the possibility that a portion of the reactions observed in this skin test are associated with an allergic response to the vaccine dilutant rather than a manifestation of protective immunity to the Leishmania antigen.

The choice of the Montenegro skin test as a method for evaluating the cellular immune response to LEISHVACINâ was based on characteristics of this response in individuals with ATL, as the presence of a developed and lasting cellular response in cured patients (with and without treatment), and a weak one (anergia) in individuals that are resistant to treatment (Salles Gomes 1939, Manson-Bahr 1987, Convit et al. 1993). The Montenegro test is considered highly specific and is used routinely in diagnosing the disease, although it is associated with recent and past infections with Leishmania, and some authors believe it can re- main positive throughout the individual's lifetime (Montenegro 1926, Manson-Bahr 1987, Nascimento et al. 1993). Populations from endemic areas present relatively high frequencies of Montenegro-positive individuals unrelated to the clinical disease, indicating possible prior exposure to the parasite with asymptomatic infection (Guerra et al. 1985, Kadaro et al. 1993, Stolf et al. 1993). A "false-positive" response in individuals with other infections may occur in a few cases (Furtado 1980). Some authors also admit the possibility of an initial test altering the response to a second test, through sensitization (Nascimento et al. 1993).

Despite such drawbacks, the Montenegro skin test is considered the safest method for evaluating the immune response to Leishmania infection (Alimohammadian et al. 1993, Convit et al. 1993, Zijlstra \& El-Hassan 1993). However, there is no doubt that a reassessment is required concerning its actual specificity when applied in populations from endemic areas for ATL, the correlation with the in vitro cellular immune response, alteration of the individual's initial response in different areas after one or more tests, and other aspects. Sensitization induced by the test itself, or the test acting as a booster in individuals previously exposed to a common antigen, may be another hypothesis to explain the rate of positive response to the final test found in the placebo group. We performed a concurrent evaluation (search for volunteers) among non-vaccinated military submitted to the Montenegro skin test and retested 65 days later, showing a conversion rate equal to that in our placebo group (data not shown).

We conclude that in terms of safety, LEISHVACIN $^{\circledR}$ can be used in human populations, even with two doses of non-autoclaved vaccine, at a concentration of $1440 \mathrm{mg}$ of protein nitrogen per dose, without causing side effects capable of jeopardizing normal daily activities in young male adults.

\section{ACKNOWLEDGEMENTS}

To Dr Getúlio B Silveira, Universidade Federal do Rio de Janeiro, for contribution in statistical analysis; to Dr Janete Cuba, Hospital Evandro Chagas, Instituto Oswaldo Cruz, for technical assistance; to Mrs Rogéria P Pinho for secretarial assistance.

\section{REFERENCES}

Alimohammadian MH, Kivanjah M, Pak F, Gaznavia A, Kharazmi A 1993. Evaluation of the efficacy of Iran leishmanin and comparison with leishmanins from Wellcome (UK) and Roma (Italy) in cured cutaneous leishmaniasis patients. Trans $R$ Soc Trop Med Hyg 87: 550-551.

Antunes CMF, Mayrink W, Magalhães PM, Costa CA, Melo MN, Dias M, Michalick M, Willians P, Oliveira 
Lima A, Vieira JBF, Schettini APM 1986. Controlled field trials of a vaccine against New World cutaneous leishmaniasis. Inst J Epidemiol 15: 572- 579.

Badaró R, Johnson Jr WD 1993. The role of Interferongamma in the treatment of visceral and diffuse cutaneous leishmaniasis. J Infect Dis 167 (Suppl. 1): 513.

Bryceson A 1987. Therapy in man, p. 847-907. In W Peters, R Killick-Kendrick (eds). The Leishmaniasis in Biology and Medicine. Clinical aspects and Control. vol 2: Academic Press, London \& New York.

Castés M, Blackwell J, Trujillo D, Formica S, Cabrera M, Zorrilla G, Rodas A, Castellanos PL, Convit J 1994. Immune response in healthy volunteers vaccinated with killed leishmanial promastigotes plus BCG. I: skin-test reactivity, T-cell proliferation and interferon-gamma production. Vaccine 12: 1041-1051.

Convit J, Ulrich M, Fernandez CT, Tapia FJ, CáceresDittmar G, Castés M, Rondón AJ 1993. The clinical and immunological spectrum of American cutaneous leishmaniasis. Trans $R$ Soc Trop Med Hyg 87: 444-448.

Cordova-Uscanga CMC, Alpuche NEA, Narváez FJA 1993. Leishmaniasis: estudio epidemiológico en una localidad de la zona endémica del Estado de Tabasco. Salud Publ de Mexico 35: 345-350.

De La Quadra J 1993. Cutaneous sensitivity to mercury and its compounds. Ann Dermatol Venereol 120: 37 42.

Desjeux P 1992. Human leishmaniasis: epidemiology and public health aspects World Health. Statistical Quarterly 45: 1-6.

Furtado T 1980. Critérios para o diagnóstico da leishmaniose tegumentar americana. An Bras Dermatol 55: 81-86.

Guerra MOP, Furrtado T, Barros GC, Sessa PA, Daher VR 1985. Infecção subclínica na leishmaniose tegumentar americana. An Bras Dermatol 60: 365369.

Handley J, Todd D, Burrows D 1993. Mercury allergy in a contact dermatitis clinic in Northern Ireland. Contact dermatitis 29: 258-261.

Isaza MR 1980. La reacion de Montenegro en la epidemiologia de la leishmaniasis sudamericana. Boletin Oficina Sanitaria Panamericana 89: 130- 136.

Kadaro AY, Ghalib HW, Ali MS, Eltoun I, Ismail A, Gaafar A, Kemp M, Kordofani AAY, Reed SG, ElHassan AM, Kharazmi A, Hag-Ali M, Mustafa MD 1993. Prevalence of cutaneous leishmaniasis along the Nile river North of Khartoum (Sudan) in the aftermath of an epidemic in 1985. Am J Trop Med Hyg 48: 44-49.

Lainson R, Shaw JJ, Silveira FT, de Souza AAA, Braga RR, Ishikawa EAY 1994. The dermal leishmaniases of Brazil with special reference to the eco-epidemiology of the disease in Amazônia. Mem Inst Oswaldo Cruz 89: 435-443.

Mallory SD 1987. Allergic contact dermatitis. Immunol Allergy Clin North Amer 7: 407-421.

Manson-Bahr PEC 1987. Diagnosis, p. 703-729. In W Peters, R Killick-Kendrick (eds). The Leishmaniases in Biology and Medicine. Clinical aspects and Con- trol, vol 2, Academic Press, London \& New York. Marzochi MCA 1992. Leishmanioses no Brasil: as leishmanioses tegumentares. J Bras Med 63: 82-104.

Marzochi MCA, Marzochi KBF 1994. Tegumentary and visceral leishmaniases in Brazil - Emerging anthropozoonosis and possibilities for their control. Cad Saú Púb 10 (Supl. 2): 359-375.

Marzochi MCA, Coutinho SG, Sabroza PC, Souza WJ 1980. Reação de imunofluorescência indireta e intradermorreação para leishmaniose tegumentar americana em moradores na área de Jacarepaguá (Rio de Janeiro): Estudo comparativo dos resultados observados em 1974 e 1978. Rev Inst Med Trop São Paulo 22: 149-155.

Mayrink W, Costa CA, Magalhães PA, Melo MN, Dias M, Oliveira Lima A, Michalick MS, Willians P 1979. A field trial of a vaccine against American dermal leishmaniasis. Trans $R$ Soc Trop Med Hyg 73: 385387.

Mayrink W, Willians P, Costa CA, Magalhães PA, Melo MN, Dias M, Oliveira Lima A, Michalick MS, Ferreira Carvalho E, Barros GC, Sessa PA, Alencar JTA 1985. An experimental vaccine against American dermal leishmaniasis: experience in the state of Espírito Santo Brazil. Ann Trop Med Parasitol 79: 259-269.

Melo MN, Mayrink W, Costa CA, Magalhães PA, Dias M, Willians P, Araújo FG, Coelho MV, Batista SM 1977. Padronização do antígeno de Montenegro. Rev Inst Med Trop São Paulo 19: 161-164.

Monjour L, Neogy AB, Vouldoukis I, Silva OA, Boisnic S, Brito MEF, Lesot A, Vignot N, Martins JS, Jarsin ML 1994. Exploitation of parasite derived antigen in therapeutic success of human cutaneous leishmaniasis in Brasil. Mem Inst Oswaldo Cruz 89: 435-443.

Montenegro J 1926. Cutaneous reaction in leishmaniasis. Archives Dermatol Syphilis 13: 187-194.

Moriearty PL, Pereira C, Guimarães NA 1978. Contact dermatitis in Salvador, Brazil. Contact dermatitis 4: 185-189.

Nadim A 1990. Leishmanization as a control measure in Iran. In UNDP/WORLD BANK/WHO/TDR Meeting on vaccines against Leishmaniasis, Belo Horizonte.

Nascimento MDSB, Alcântara-Neves NM, Muniz MEB, Nunes SF, Paranhos M, Pontes de Carvalho LC 1993. Induction and modulation of the immune response to Leishmania by Montenegro skin test. Trans $R$ Soc Trop Med Hyg 87: 91-93.

Oliveira-Filho AM, Melo MTV 1994. Vectors control importance on leishmaniasis transmission. Mem Inst Oswaldo Cruz 89: 4451-456.

Olliaro PL, Bryceson ADM 1993. Practical progress and new drugs for changing patterns of leishmaniasis. Parasitol Today 9: 323-328.

Pessoa SB 1941. Segunda nota sobre a vacinação preventiva na Leishmaniose Tegumentar Americana com leptomonas mortas. Rev Paulista Med 19: 1-9.

Pessoa SB, Pestana BR 1940. Ensaio sobre a vacinação preventiva na Leishmaniose Tegumentar Americana com germes mortos. Rev Biol Higiene 10 : 112-118. Salles Gomes L 1939. A intradermorreação de 
Montenegro na leishmaniose e outras pesquisas afins. Brasil Méd 49: 5-15.

Scarpa C, Kokelj F, Stinco G, Lavaroni G 1992. Allergic contact dermatitis in Trieste from 1987-1991. Aller Immunol Paris 24: 390-392.

Sokal JE 1975. Measurement of delayed skin-test responses. N Engl J Med 293: 501-502.

Stolf HO, Alencar Marques S, Marques EA, Yoshida ELA, Dillon NL 1993. Surto de leishmaniose tegumentar em Itaporanga São Paulo (Brasil). Rev Inst Med Trop São Paulo 35: 437-442.

Voller A, Bartlett A, Bidwell DE 1976. Enzyme immunoassays with special reference to ELISA thecniques. J Clin Pathol 31: 507-520.

Zijlstra EE, El-Hassan AM 1993. Leishmanin and tuberculin sensitivity in leishmaniasis in the Sudan with special reference to kala-azar. Trans $R$ Soc Trop Med Hyg 87: 425-427. 